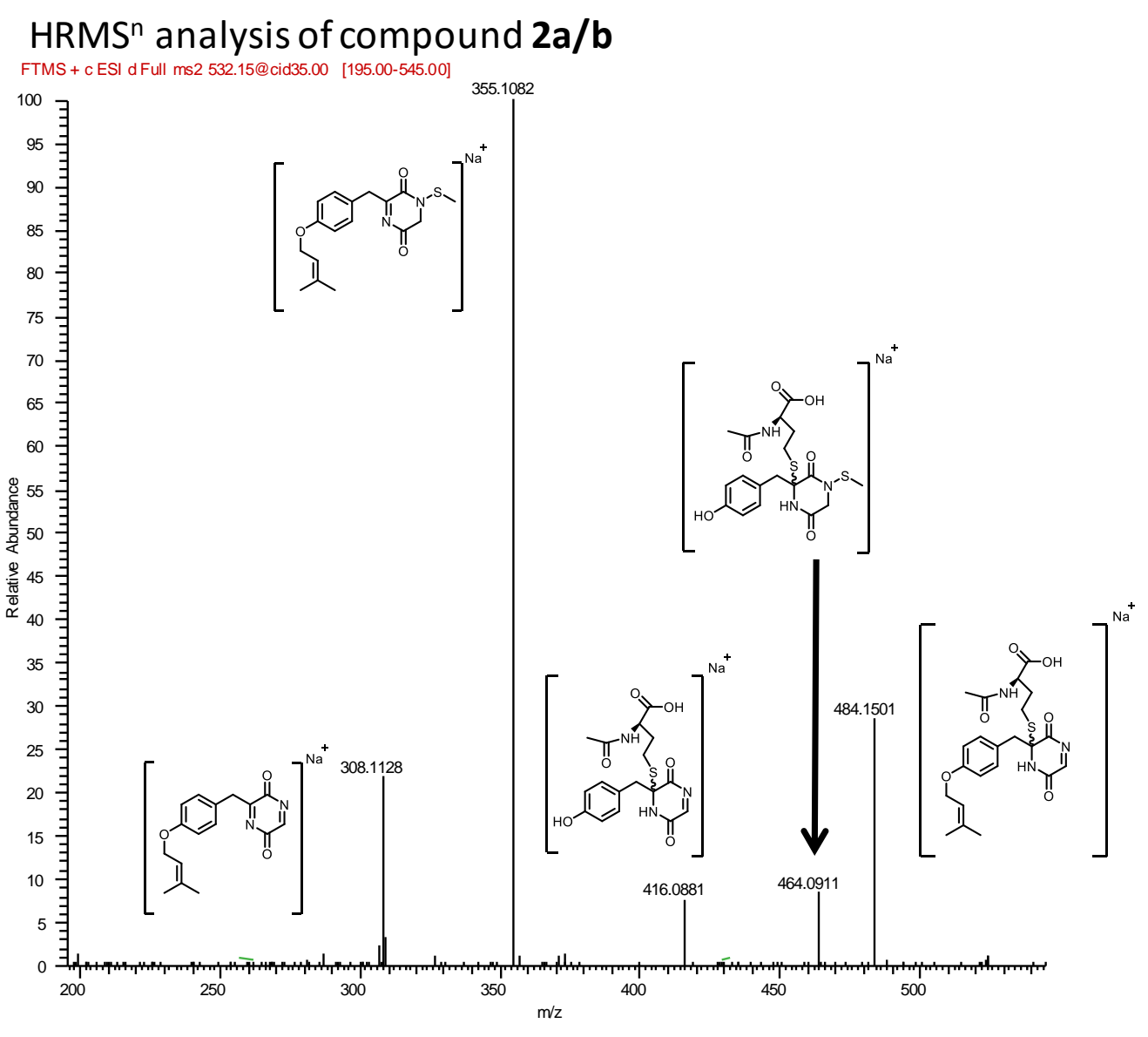

\title{
HRMS $^{n}$ analysis of compound $\mathbf{3}$
}

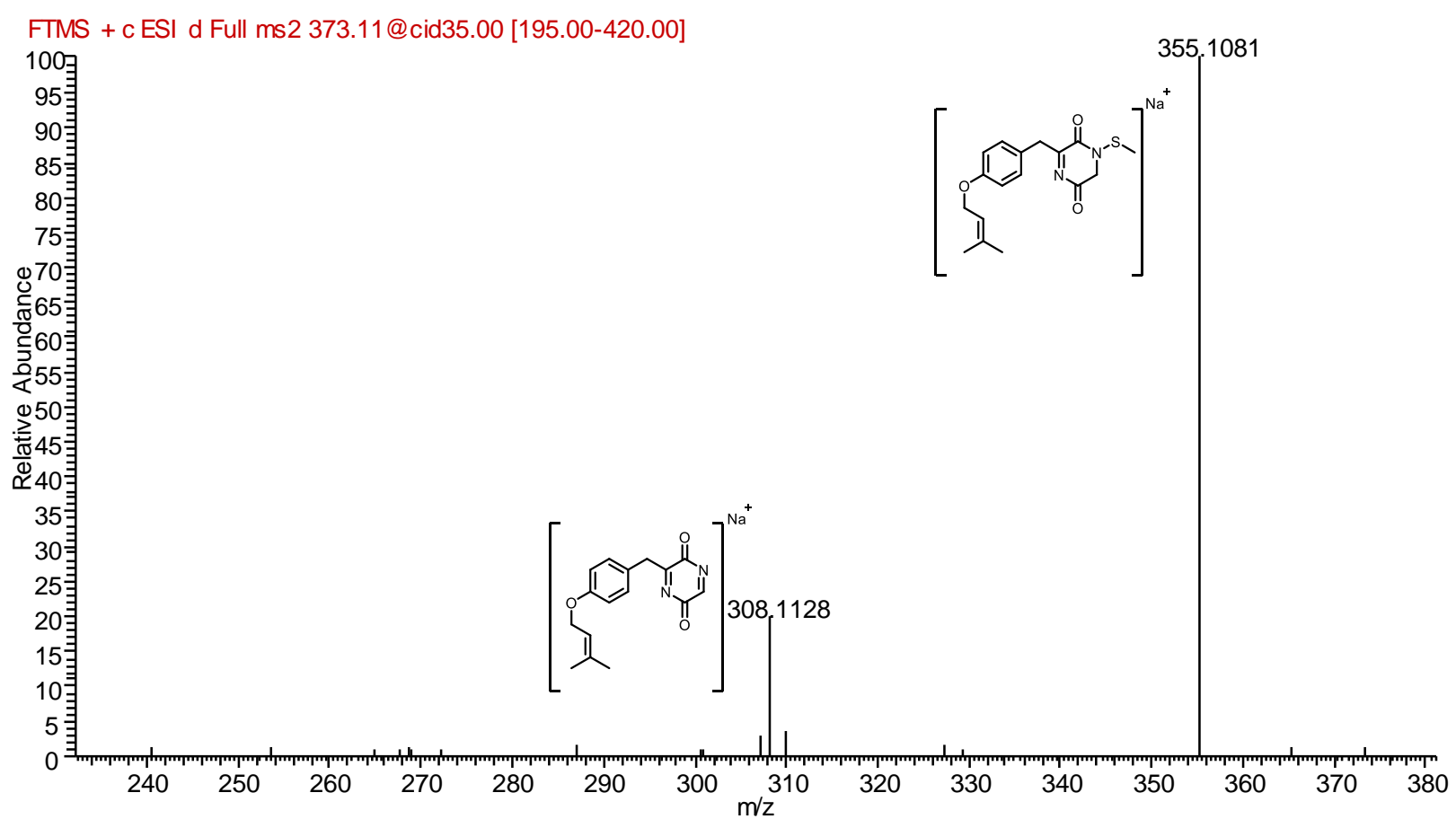


HRMS $^{n}$ analysis of compound 5

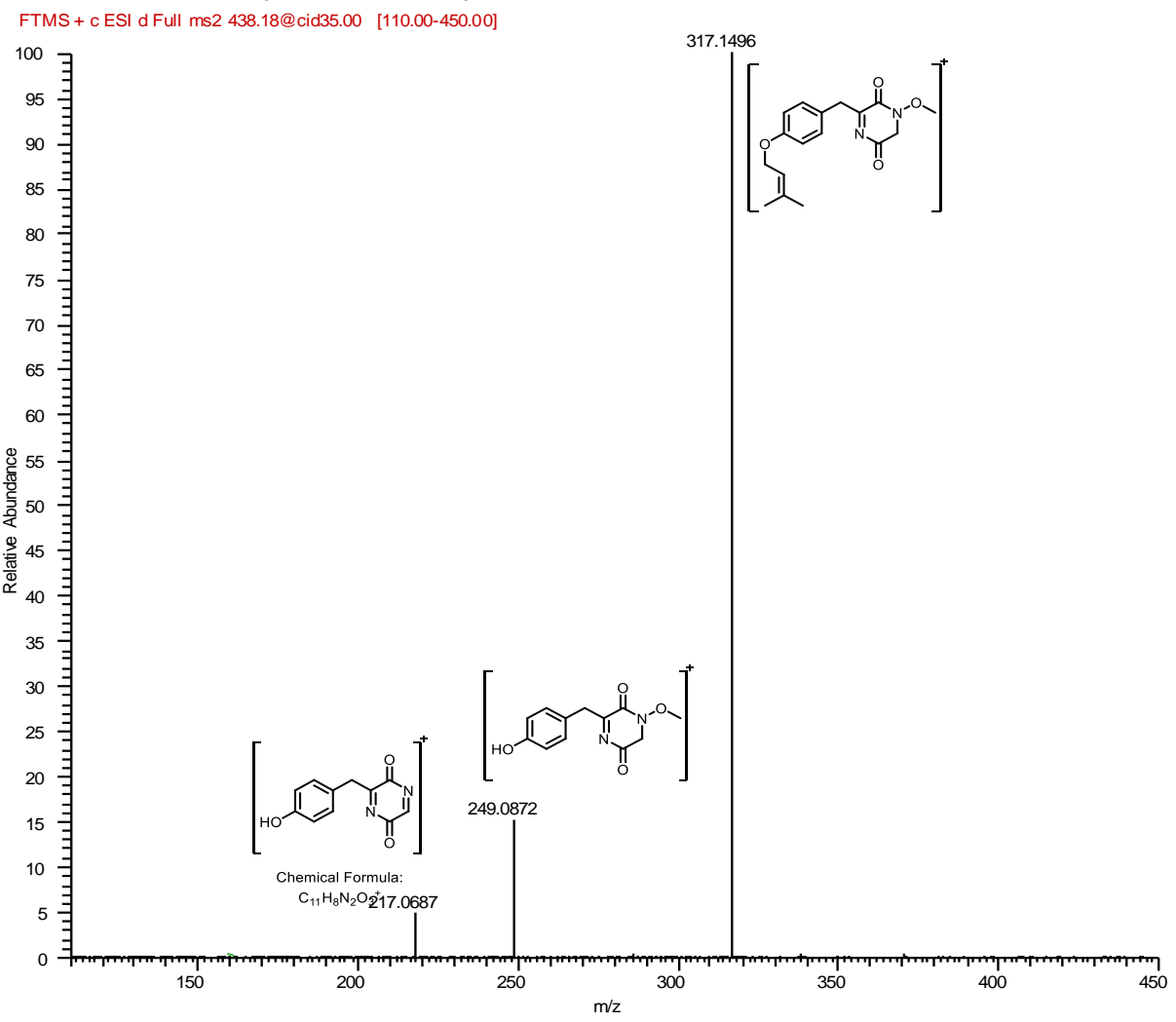

HRMS $^{n}$ analysis of compound 6

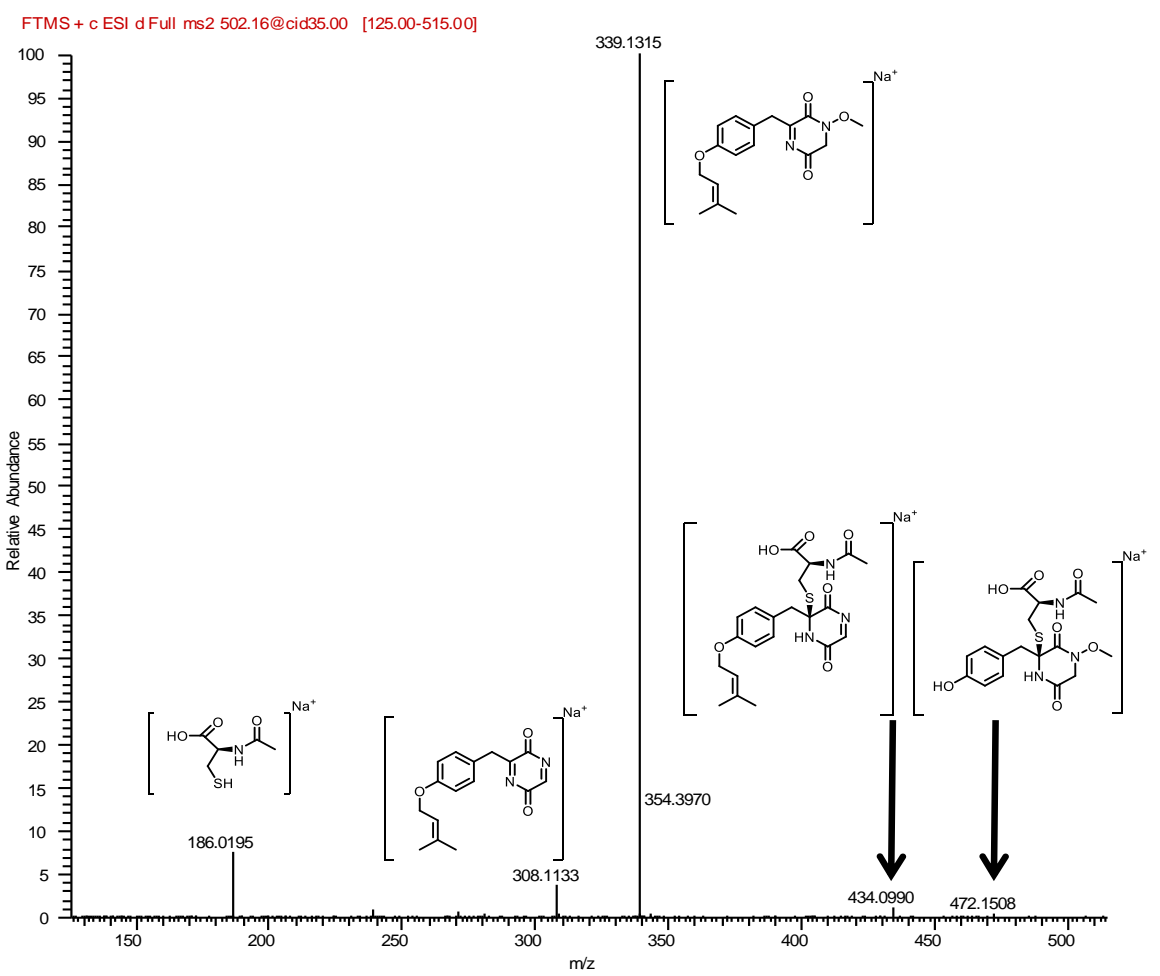



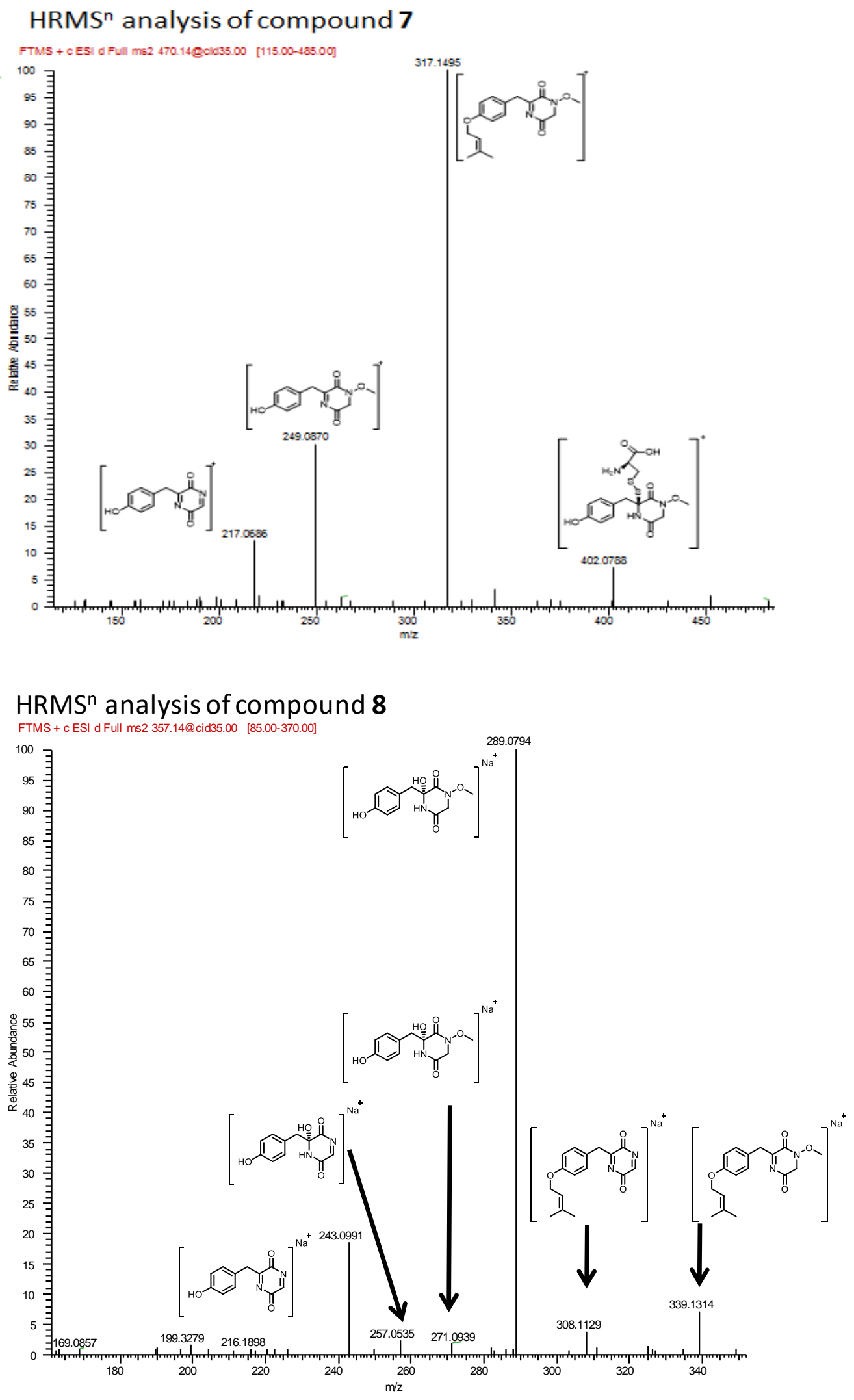